\title{
Preparation of Graphite Dispersed Copper Composite on Copper Plate with Spot Welding
}

\author{
Abdul Muizz Mohd Noor ${ }^{* 1}$, Yoshikazu Ishikawa ${ }^{* 2}$ and Seiji Yokoyama \\ Department of Mechanical Engineering, Toyohashi University of Technology, Toyohashi 441-8580, Japan
}

\begin{abstract}
It was attempted that copper-graphite composite was prepared only on the surface of a copper plate using a spot welding machine. Experiments were carried out with changing the compressive load, the repetition number of the compression and the electrical current in order to study their effects on carbon content and Vickers hardness of the composite. Generally, the carbon content of the composite prepared without an electrical current flow was smaller than that prepared with an electrical current flow. The former composite was prepared with that relatively small angular graphite particles were pushed into the copper plate. In the case of flowing electrical current, graphite particles was heated, and partially or wholly dissolved into molten copper. Therefore, the latter composite was prepared with undissolved graphite and precipitated graphite from the copper melt. In addition, the Vickers hardness of the copper matrix in the composite prepared without an electrical current flow was larger than that prepared with an electrical current flow, because energization heated and annealed the composite. The Vickers hardness of the copper matrix in the composite and the volume fraction of graphite were expressed by the rule of mixtures. [doi:10.2320/matertrans.M2017073]
\end{abstract}

(Received March 6, 2017; Accepted May 29, 2017; Published July 25, 2017)

Keywords: graphite-dispersed copper composite, spot welding, particle precipitation, carbon content, Vickers hardness, rule of mixtures

\section{Introduction}

Copper brushes are used in small and large DC motors. The materials for sliding contact such as the brushes have been widely used. ${ }^{1)}$ They are important materials to determine the lifetimes, performances and safety of the products. These materials require good electrical and thermal conductivities, low thermal expansion, good wear resistance and good lubricities, depending on the products. Copper has good electrical and thermal conductivities but does not have wear resistance, whereas graphite has self-lubricant property as well as a good electrical conductivity. Therefore, coppergraphite composite promises to those properties for sliding contact. $^{2,3)}$ Many methods have been developed to prepare graphite dispersed copper composite. The problem which is common to these methods is that copper does not wet on graphite. Usually, this composite has been produced with sintering. In this process, alloy elements are added to improve the wetting. ${ }^{4,5)}$ In our previous works, it has been found that the wetting of molten copper to graphite is improved at temperature approximately $2100 \mathrm{~K}$ and above. $\left.{ }^{6}\right)$ This suggests that the composite is produced by holding the mixture of copper and graphite at a higher temperature.

The bulk graphite dispersed composites are needed in some cases, and the composites prepared only on the surface are demanded in other cases. One of the heating machines which can locally heat materials to high temperature is a spot welder. Then, graphite particles on a copper plate were spot-welded in order to prepare the copper-graphite composite only on the copper surface. Usually, operation parameters of a spot welding are a compressive load and an electrical current flow. The spot welding has been carried out on these most suitable conditions. In addition, the sequential operation consisted of placement of the graphite particles on the

\footnotetext{
${ }^{* 1}$ Graduate Student, Toyohashi University of Technology, Corresponding author, E-mail: muizz@tf.tut.ac.jp

${ }^{* 2}$ Graduate Student, Toyohashi University of Technology
}

copper plate, compression and spot welding were repeated because graphite particles did not adhere to the copper plate by a one-time spot welding. Influences of the compressive load, the electrical current flow and the repetition number of the operation on the Vickers hardness as well as the carbon content were studied in this work.

\section{Experimental}

Commercially available pure copper plate (the purity: 99.9 mass \%) and graphite particles (99.97 mass\%) with $50 \mu \mathrm{m}$ in average size were used in this study. The copper plate which was cut from the plate was $15 \mathrm{~mm}$ width by $50 \mathrm{~mm}$ long by $1 \mathrm{~mm}$ thickness. To remove unnecessary substances such as grease, laboratory dust and so on, the copper plate was cleaned with an ultrasonic cleaner $(45 \mathrm{kHz}$, $300 \mathrm{~W}$ ) filled with acetone. Graphite powder was grounded with an agate mortar and pestle. The ground particles were passed through the sieve which opening was $20 \mu \mathrm{m}$. SEM image of the graphite particles used for this study was shown in Fig. 1. The particles were approximately $5 \mu \mathrm{m}$ in average size. The relatively large and small particles were

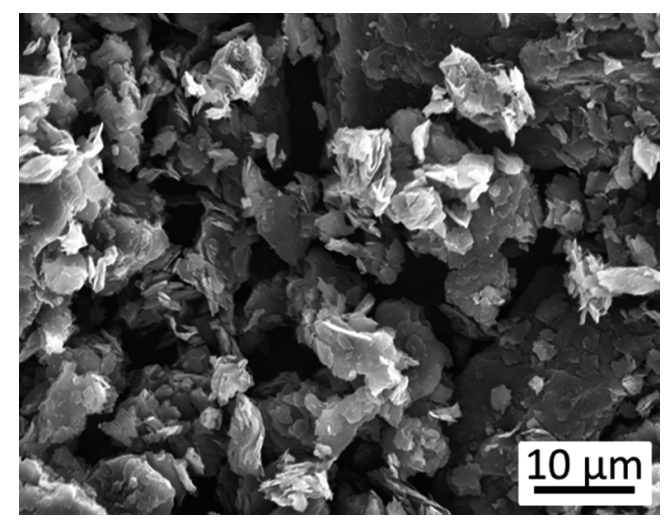

Fig. 1 SEM image of graphite particles used in this work. 
flat and angular in shape respectively.

The graphite particles were placed between the two copper plates, as shown in Fig. 2. The layer of graphite particles sandwiched between two copper plates was approximately $0.8 \sim 1 \mathrm{~mm}$ in height. The sample was fixed by a wooden clip so that the graphite particles did not fall down during welding.

The sample was set between the two copper electrodes of the spot welding machine. Subsequently, it was compressed by the electrodes. The compressive loads were $0.0,1.3,3.5$ and $5.7 \mathrm{kN}$. Because the deformed area was approximately $100 \mathrm{~mm}^{2}$, the compressive stresses were $0.0 \mathrm{MPa}, 1.3 \mathrm{MPa}$, 3.5 $\mathrm{MPa}$ and 5.7 MPa respectively. Pulsed electrical current was energized for $50 \mathrm{~ms}$ every pulse 6 times (total $300 \mathrm{~ms}$ ) by the one spot welding to the sample during the compression. The electrical currents were $0 \mathrm{kA}, 10 \mathrm{kA}$ and $16 \mathrm{kA}$.

A series of operations consisted of the introduction of graphite particles, the compression, and the ultrasonic cleaning was performed repeatedly. The surface and the cross section of the copper plate were observed using a SEM (scanning electron microscope) and a laser microscope. Carbon content in the surface was analyzed with an EDX (Energy dispersive X-ray spectroscopy) equipped with the SEM. Therefore, the carbon content was the value for the surface of the plate. The quantity of graphite adhered to the copper plate was evaluated through its carbon content. The carbon contents at seven different places were measured with an area analysis of the EDX. The measured area size was approximately $0.02 \mathrm{~mm}^{2}$. The carbon content was evaluated with the mean of seven measured values. The maximum scattering of the carbon content was approximately $\pm 15 \%$ for the mean value. Vickers hardness was measured with a microhardness tester on the load condition of $0.98 \mathrm{~N}$. The hardness was measured at five positions from the center of

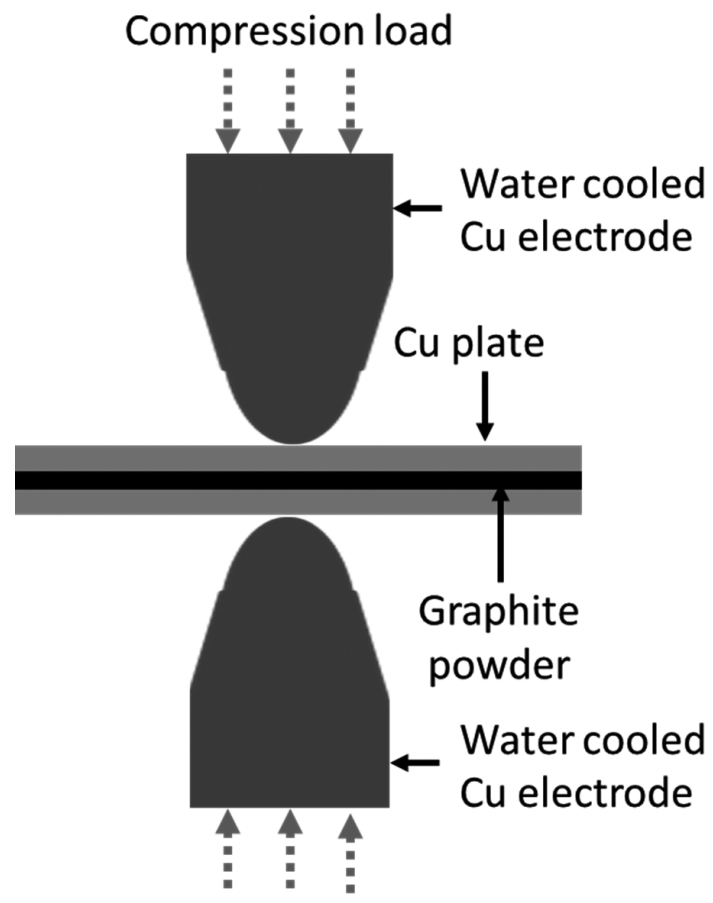

Fig. 2 Schematic of main part of apparatus for preparation of graphite dispersed copper composite with resistant spot welder. to the periphery of the part deformed by the compression. The hardness was evaluated with the mean of ten measured values. In addition, the hardness was measured at the matrix of copper in the composite. The maximum scattering of the measured hardness was $\pm 10 \%$ for the average value.

\section{Results and Discussion}

\subsection{Quantity of adhered graphite}

After the compression, two copper plates prepared without an electrical current flow were not attached each other, but two plates prepared with an electrical current flow were attached each other on certain occasions. This suggested that the two copper plates were spot-welded. However, they could be separated manually. This adhesion was easy to occur when the compressive load and/or the electrical current flow were large. Even if the compressive load and the electrical current flow were large, this spot welding did not always occur. This meant instability of this preparation method. Furthermore, the electrode and the copper plate were never welded to each other. The copper plate was cleaned with the ultrasonic cleaner after the spot welding. The particles which did not come off the plate even with this ultrasonic cleaning were considered to be the particles which stuck firmly to the copper plate.

Figure 3 showed the relation between carbon content in the copper plate and the repetition number of the compression, when an electrical current was not energized through the sample at compression. Generally, after the carbon content steeply increased with the increase in the repetition number, it slightly increased with the repetition number. In addition, the carbon content increased with an increase in the compressive load. Here, the carbon content in the upper copper plate was almost as the same as in the lower copper plate. There was no systematic difference in both the carbon contents.

Figure 4 showed the relation between carbon content in the copper plate and the repetition number of the compression, when an electrical current was energized through the sample at compression. The carbon content increased with an increase in the compression load as well as the repetition number. These behaviors of the carbon contents were quali-

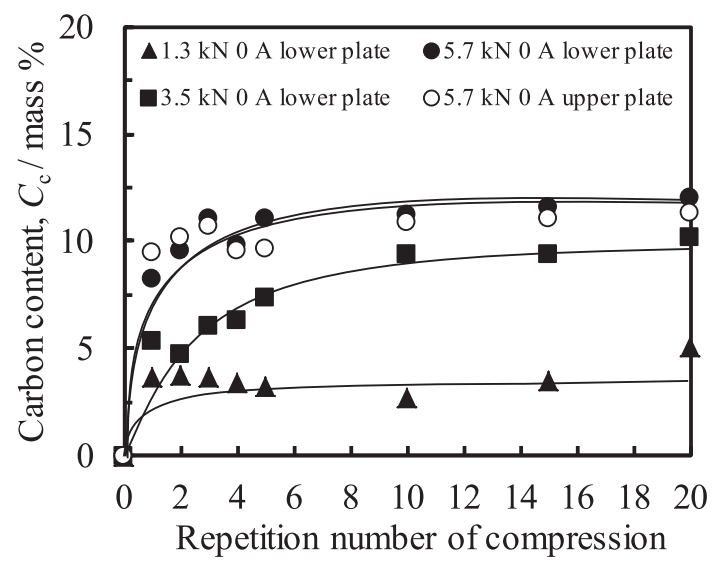

Fig. 3 Relation between carbon content and repetition number of compression for composite prepared without an electrical current flow. 
tatively the same as those for the composites prepared without an electrical current flow. In addition, the carbon content increased with an increase in the electrical current flow. In comparison with the carbon content as shown in Fig. 3, the carbon content in the composite prepared with an electrical current flow was approximately five times larger than that without an electrical current flow.

\subsection{Graphite particles in composite}

Figure 5 showed the surface of the composite prepared without an electrical current flow. As shown in Fig. 5 (a), the graphite particles were hardly observed in the macroscopic image. The particles were observed on the plate before the ultrasonic cleaning, whereas most of them were removed by the ultrasonic cleaning. Microscopically, the graphite particles locally adhered to the copper plate, as shown Fig. 5 (b). Because there were a lot of places where the graphite particles distributed as shown Fig. 5 (b), it could be assumed from the macroscopic view point that the graphite particles distributed sparsely. As shown in Fig. 5 (b), the hollows like craters were observed on the plate. These showed traces where the particles had been plunged. Figure 5 (c) showed the cross section of the plate. Only small particles with sharp edge were plunged on the copper plate surface. Therefore, the mechanism of plunging the graphite particles in a copper plate could be explained as follows. When a flat particle, which meant the relatively large particle, was plunged into a

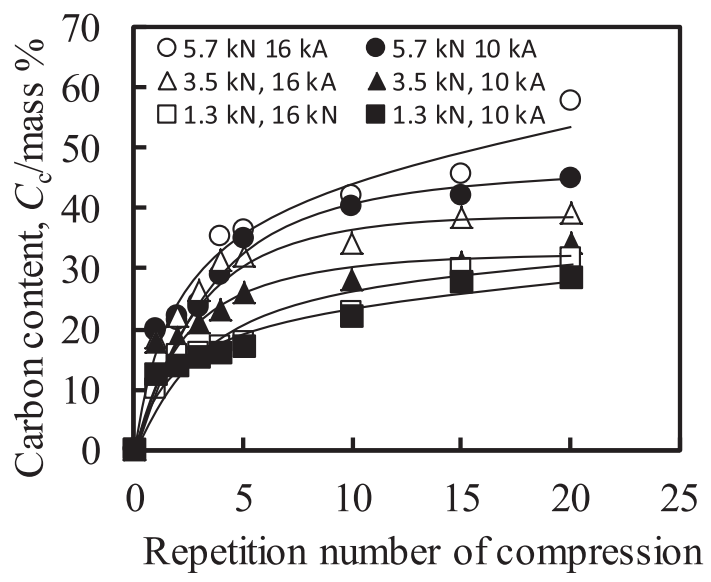

Fig. 4 Relation between carbon content and repetition number of compression for composite prepared with an electrical current flow. copper plate as shown in Fig. 6 (a), the pressed particle made a dent on the plate surface. Because this particle was only pressed, particle did not adhere to the copper plate and was easily removed from the plate by the ultrasonic cleaning. When a particle with sharp edge, which meant relatively small particle, was plunged into a copper plate as shown in Fig. 6 (b), the compression made the particle stuck in the plate. This particle did not bond with copper chemically but was fastened by deformation of the copper plate. Therefore, the ultrasonic cleaning could not remove this plunged particle.

Figure 7 showed an example of the composite prepared using an electrical current flow. Numerous graphite particles adhered to the copper plate, as shown in Figs. 7 (a) and (b). Except for the graphite particles sandwiched between graphite particles on the copper plates, the number of the particles on the plate before the ultrasonic cleaning was almost the same as that after the cleaning. Figure 7 (c) showed the cross section of the plate near the surface. The graphite particles were consolidated into an aggregate form. Its cross section was looked to be the section of a layer. This graphite aggregate was on the copper plate and was composed of graphite particles and copper. In addition, the shapes of graphite particles in the aggregate became spherical, and their sizes became large, in comparison with those of the graphite particle before the experiment. Figure 7 (d) showed the cross section of the composite where the copper plates were spot-welded. A lot of graphite particles were observed not only at the surface of the copper but also in the copper. The graphite particles were polygonal in shape and composed of graphite and metallic copper. The surfaces and the cross sections of the

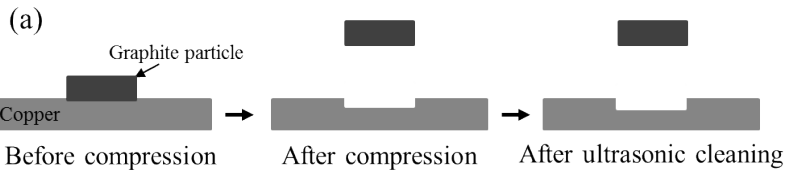

(b)

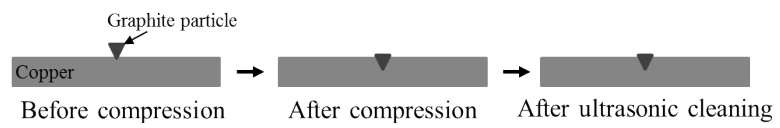

Fig. 6 Outline of mechanism for formation of graphite dispersed coppe composite prepared without electrical current flow. Figure (a) showed the mechanism for a relatively large and flat particle. Figure (b) showed the mechanism for a relatively small and angular particle.
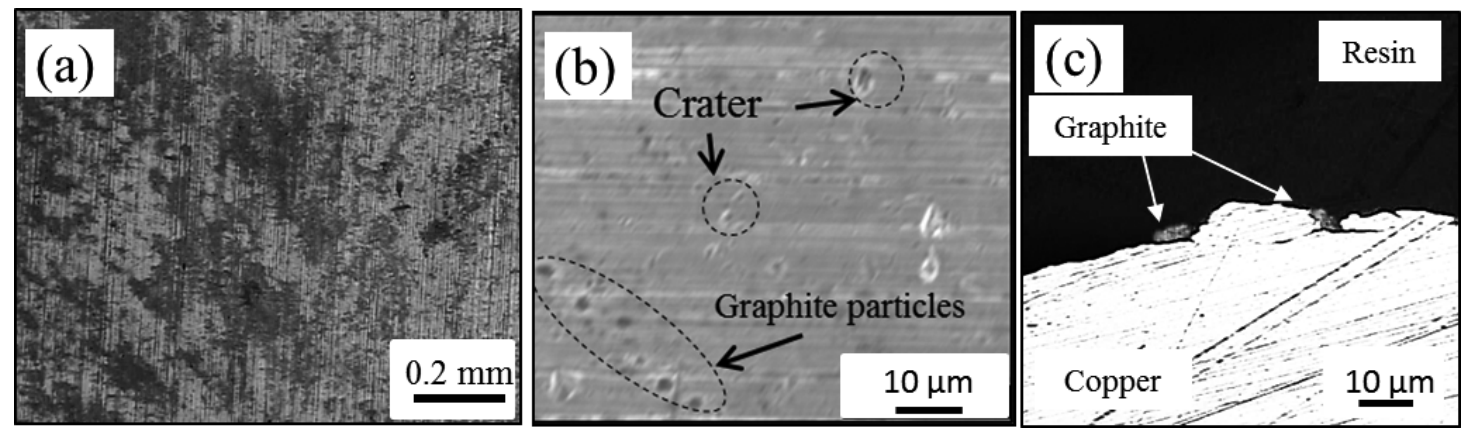

Fig. 5 Surface and cross section of composite prepared without an electrical current flow. (The repetition number: 20 , the compressive load: 5.7 kN, without electrical current) Figures (a) and (b) macroscopically and microscopically showed the surface of the copper plate respectively. Figure (c) showed the cross section of the copper plate. 

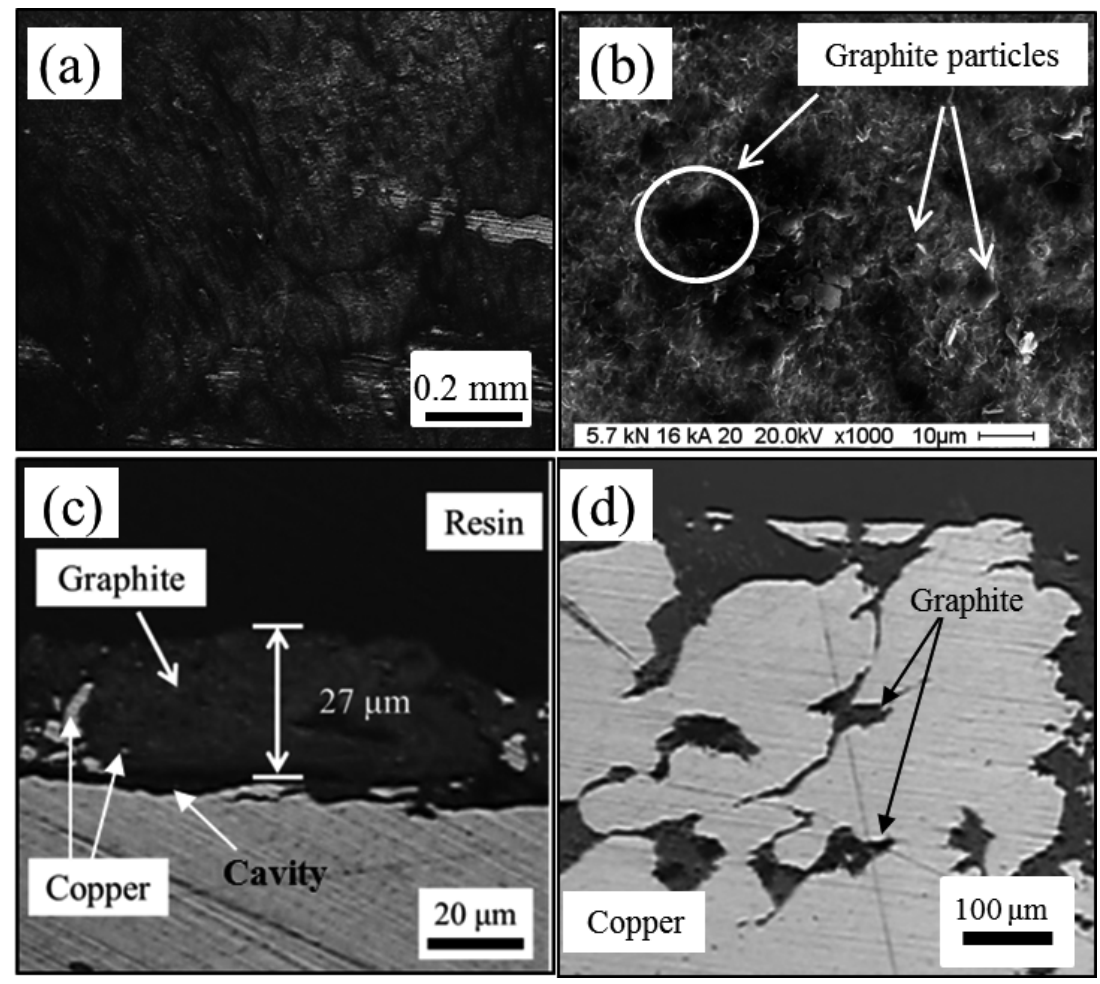

Fig. 7 Surface and cross section of composite prepared with an electrical current flow (The repetition number: 20 , the compressive load: $5.7 \mathrm{kN}$, the electrical current: $16.7 \mathrm{kA}$ ). Figures (a) and (b) macroscopically and microscopically showed the surface of the copper plate respectively. Figure (c) showed the cross section of the copper plate. Figure (d) showed the cross section of the copper at the place where the copper plates were welded each other.

composites prepared on the different compressive load and electrical current were almost the same as the one shown in Fig. 7.

Here, it was assumed that electrical current flowed through a graphite plate instead of graphite particles layer. When an electrical current flowed through the graphite plate, the graphite plate was heated by the Joule's heat as:

$$
C_{\mathrm{p}} \frac{A L d}{M_{\mathrm{C}}}\left(T-T_{298}\right)=\rho \frac{L}{A} I^{2} t
$$

where $A$ was the cross-sectional area of the plate $\left[\mathrm{m}^{2}\right], L$ the thickness of the plate [m], $d$ the density of graphite, $M_{\mathrm{c}}$ the molar mass of graphite $[\mathrm{kg} / \mathrm{mol}], C_{\mathrm{p}}$ the molar heat capacity of graphite at constant pressure $\left[\mathrm{J} \cdot \mathrm{mol}^{-1} \cdot \mathrm{K}^{-1}\right], I$ the electrical current $[\mathrm{A}], \rho$ the electrical resistivity $[\Omega \cdot \mathrm{m}]^{7)}, t$ the time $[\mathrm{s}]$ and $T_{298}$ the temperature of $298 \mathrm{~K}$. From this equation, the temperature of the graphite plate, $T$, was expressed as:

$$
T=\frac{\rho I^{2} t M_{\mathrm{C}}}{C_{\mathrm{p}} A^{2} d}+T_{298}
$$

Table 1 depicted the values used for the calculation. The value of the heat capacity was extrapolated to $10000 \mathrm{~K}$ based on the reported values from $298 \mathrm{~K}$ and $1500 \mathrm{~K}{ }^{8)}$ Similarly, the molar heat capacity was obtained by averaging the values from $298 \mathrm{~K}$ to $10000 \mathrm{~K}$. This averaging was used to simplify the calculation. Figure 8 showed the relation between the temperature and the electrical current. Assuming that the electrical resistance was ten times $(10 \rho)$ or one tenth $(\rho / 10)$ as large as the value listed in Table 1 , the calculated lines were also shown in this figure for reference. The temperature of the graphite plate increased with an increase in

\begin{tabular}{|c|c|c|c|c|c|}
\hline $\begin{array}{l}\text { Area, } \\
A / \mathrm{m}^{2}\end{array}$ & $\begin{array}{l}\text { Density, }{ }^{11)} \\
d / \mathrm{kg}^{-3} \mathrm{~m}^{-3}\end{array}$ & $\begin{array}{l}\text { Molar mass, } \\
M_{\mathrm{c}} / \mathrm{kg} \cdot \mathrm{mol}^{-1}\end{array}$ & $\begin{array}{l}\text { Electrical } \\
\text { resistance }^{7)} \text {, } \\
\rho / \Omega \mathrm{m}\end{array}$ & $\begin{array}{l}\text { Heat capacity }{ }^{8)} \text {, } \\
C \mathrm{p} / \mathrm{J} \cdot \mathrm{mol}^{-1} \cdot \mathrm{K}^{-1}\end{array}$ & $\begin{array}{l}\text { Time, } \\
t / \mathrm{s}\end{array}$ \\
\hline $1.0 \times 10^{-4}$ & $2.3 \times 10^{3}$ & $12 \times 10^{-3}$ & 0.0138 & 18.77 & 0.3 \\
\hline
\end{tabular}

Table 1 Values used for calculation.

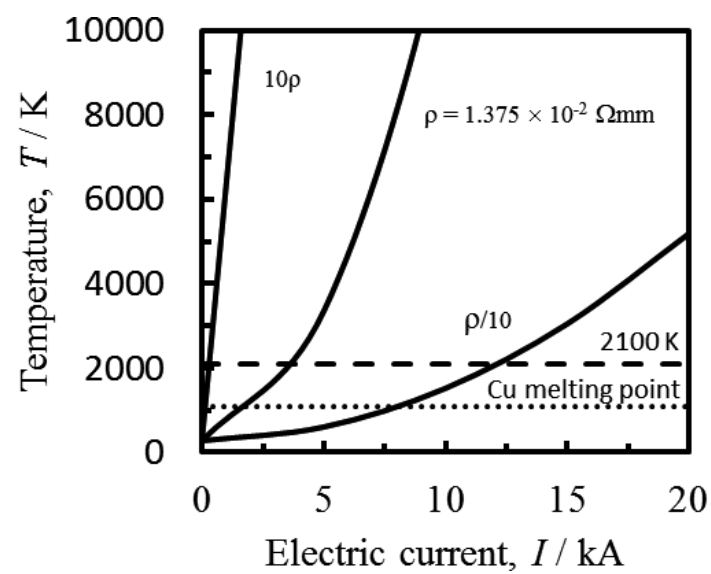

Fig. 8 Relation between calculated temperature of graphite plate and electrical current.

the electrical current and increased with an increase in the electrical resistance. This calculation suggested that copper was heated by the heat conduction from the graphite with an increase in the electrical current. As shown in Fig. 8, the temperature of the graphite plate was higher than a copper melting point and easily reached beyond $2100 \mathrm{~K}$ when the 
electrical current of $10 \mathrm{kA}$ or $16 \mathrm{kA}$ flowed through the graphite plate.

In our previous study ${ }^{6}$, it was found that saturated carbon content in a molten copper steeply increased with the temperature when it was held at the temperature approximately $2100 \mathrm{~K}$. In addition, a molten copper which was held above this temperature could wet with graphite crucible. ${ }^{6)}$ In the case that the composite was prepared with an electrical current flow, the mechanism of formation of graphite particles on copper plate could be explained in Fig. 9. Namely, when a high electrical current was energized through a plunged particle, copper around the graphite particles was melted by the Joule's heat. As described earlier, the graphite particles were different from the particles before the experiment. This suggested that a copper around the graphite particle was heated to temperature above approximately $2100 \mathrm{~K}$. Therefore, the graphite particles dissolved into the molten copper fully or partially. The graphite particles precipitated from the liquid copper under cooling. This dissolution and precipitation caused not only that the particles were consolidated into an aggregate form but also that the graphite particles became round. Furthermore, the graphite particles could not be eliminated by the ultrasonic cleaning because the molten copper could wet the graphite particle. Copper was observed between the graphite particles at the upper part of the copper plate. This suggested that the molten copper rose up through capillarity. In the case that the adhesion due to the spot welding occurred, the part of melted copper was enlarged deeply in the plate. This mean the temperature of the melt part was higher. During cooling, the graphite precipitated from the melt which the graphite dissolved into.

\subsection{Vickers hardness}

As described earlier, the hardness was measured from the center of to the periphery of the spot welding. It was judged from the maximum scattering that the measured hardness did not depend on the distance from the center. Figure 10 showed the relation between the Vickers hardness and the repetition number of compression, in the case that the composite was prepared without an electrical current flow. Generally, the Vickers hardness steeply increased with the increase in the repetition number. Subsequently, it slightly increased with the repetition number. The Vickers hardness increased with an increase in the compressive load. These dependencies of Vickers hardness on the repetition number and compressive load were as similar as the dependencies of the carbon content.

Figure 11 showed the relation between the Vickers hardness and the repetition number of compression, in the case that the composite was prepared with an electrical current flow. Generally, the Vickers hardness decreased at the first compression. This resulted from the annealing, as described later. Subsequently, it increased with an increase in the repetition number of compressive load and the electrical current value. The Vickers hardness increased with an increase in the compressive load and an increase in the electrical current. Compared to the hardness in Fig. 10, the hardness of the composite prepared with an electrical current flow was smaller than that prepared without an electrical current flow.

Figure 12 showed the relation between the Vickers hardness and the carbon content. Generally, the Vickers hardness linearly increased with an increase in the carbon content. In addition, the hardness of the composite prepared without an electrical current flow was larger than the composite prepared with an electrical current flow. The dependencies of the hardness on the carbon content, which were the gradi-

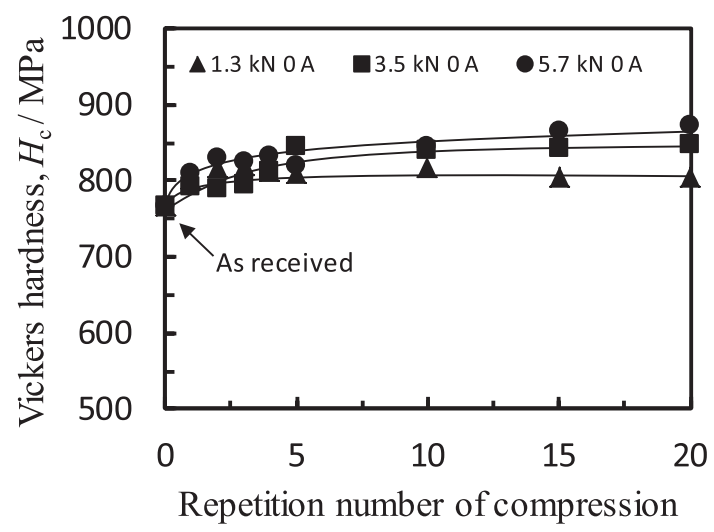

Fig. 10 Relation between Vickers hardness and repetition number of compression for composite prepared without an electrical current flow.

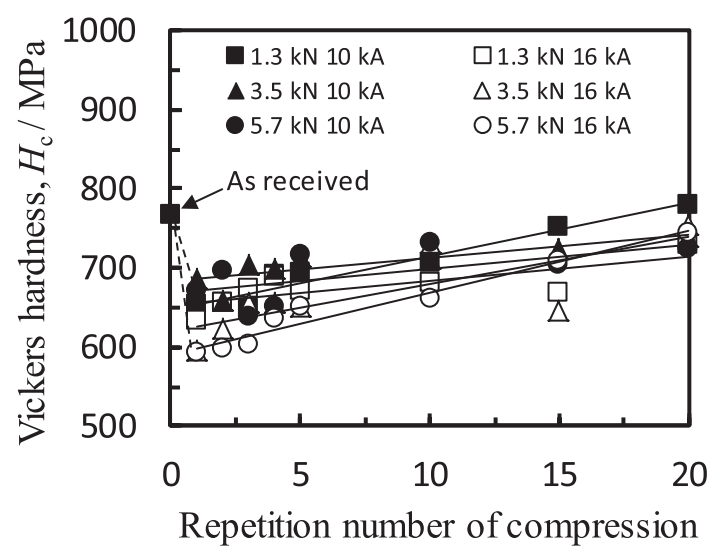

Fig. 11 Relation between Vickers hardness and repetition number of compression for composite prepared with an electrical current flow.

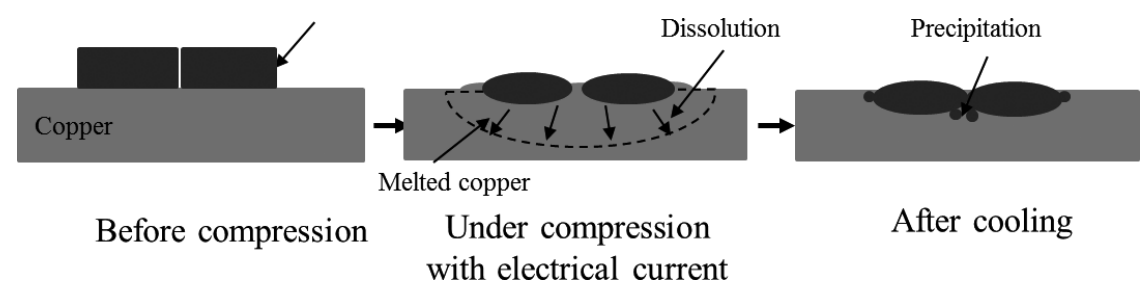

Fig. 9 Outline of mechanism for formation of graphite dispersed copper composite prepared with an electrical current flow. 


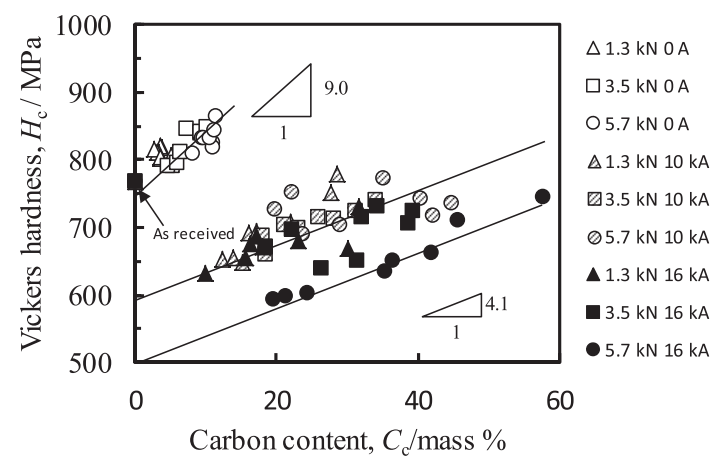

Fig. 12 Relation between Vickers hardness and carbon content.

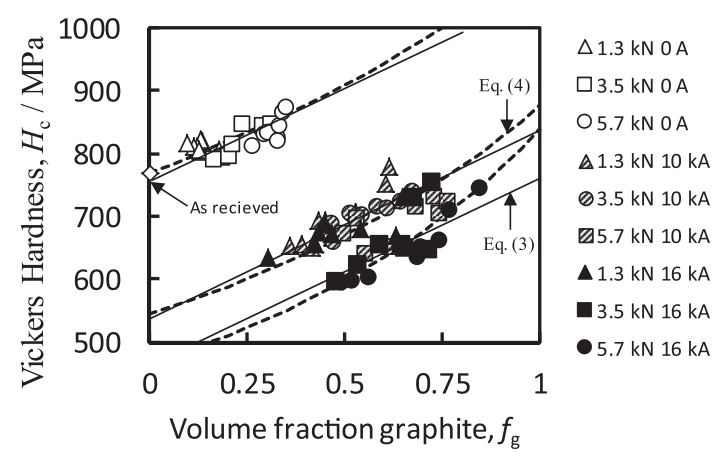

Fig. 13 Relation between Vickers hardness and volume fraction. ents of the straight lines given by the regression analysis, were classified into two groups. One group is for the composite which was prepared without an electrical current flow. The gradient was approximately $9.0 \mathrm{MPa} /$ mass $\%$ C. Another group was for the composite which were prepared with an electrical current flow. There were two regression lines for the composite which were prepared with an electrical current flow. The lower and the upper lines were for the composites with and without the adhesion due to the spot welding respectively. These gradients were approximately 4.1 $\mathrm{MPa} / \operatorname{mass} \% \mathrm{C}$.

As shown in Fig. 12, the intercept which was the hardness at the carbon content of zero mass\% expressed the hardness of the copper matrix. The hardness of the copper matrix for the composite prepared without the electrical current flow was the highest and same with the initial copper plate. The hardness of the copper matrix for the composite prepared with the electrical current flow was lower than that without the current flow because of the annealing due to the Joule's heat. In addition, the hardness of the copper matrix with the adhesion due to the spot welding was smaller than that without the adhesion. As described earlier, the composite with the adhesion was annealed sufficiently because the temperature at its surface of it was higher than that without the adhesion.

The dependency of the hardness on the carbon content proved that if the composite was reinforced only by the solid-solution strengthening. Because most carbon existed as graphite, the relation between the hardness and the carbon content showed only the empirical correlation between them. The rule of mixtures expressed the properties of a bulk composite such as stress, elastic modulus, strain etc. The equations which expressed the upper and the lower bounds for the properties of particle-reinforced composites were known. ${ }^{9)}$ In this study, the composite material was prepared only on the copper surface. In addition, the hardness of an only copper matrix in the composite was measured. Applying these equations which gave the bounds to the hardness of this composite, the following equations were obtained. ${ }^{10)}$

$$
\begin{gathered}
H_{\mathrm{C}}=H_{\mathrm{Cu}}\left(1-f_{\mathrm{g}}\right)+H_{\mathrm{g}} f_{\mathrm{g}} \\
\frac{1}{H_{\mathrm{C}}}=\frac{1-f_{\mathrm{g}}}{H_{\mathrm{Cu}}}+\frac{f_{\mathrm{g}}}{H_{\mathrm{g}}}
\end{gathered}
$$

where $H$ was the hardness [Pa], $f$ the volume fraction, subscript $\mathrm{C}, \mathrm{Cu}$ and $\mathrm{g}$ indicated the composite, copper and graphite respectively.

Figure 13 showed the relation between the Vickers hardness and the volume fraction of graphite. Here, the volume fraction of graphite was calculated by using mass percentage of carbon, densities of graphite and copper. ${ }^{11,12)}$ The solid line and the broken line were given by the regression analysis based on eq. (3) and eq. (4) respectively. Both lines expressed well the relations between the hardness and the volume fraction of graphite. The hardness of the copper matrix, $H_{\mathrm{cu}}$, and the hardness of graphite, $H_{\mathrm{g}}$, were given by the hardness at the volume fraction of graphite of zero $\left(f_{\mathrm{g}}=0\right)$ and one $\left(f_{\mathrm{g}}=1\right)$ respectively. The following things could be said on the hardness of the copper matrix given from these two expressions. The hardness of the copper matrix for the composite prepared without the electrical current flow was the highest. The value for without the adhesion in case of the electrical current flow was the second highest while the adhesion with the electrical current flow was the lowest. These properties originated from being annealed or not, and also annealing temperature, as described earlier. Similarly, the following properties could be found on the hardness of the graphite, $H_{\mathrm{g}}$, given from these two expressions. The hardness of the graphite for the composite prepared without the electrical current flow was the highest, while without the adhesion but with the electrical current flow was second highest. With the adhesion and electrical current flow, the hardness was the lowest. However, the hardness of the graphite in the copper composite should not be changed by the preparation conditions, because the graphite particle was solid. Here, the value of $H_{\mathrm{Cu}}$ given by eq. (3) and eq. (4) were different so as the value of $H_{\mathrm{g}}$. This resulted from that those values obtained from a regression analysis based on eq. (3) and eq. (4).

In this study, the hardness measurement was performed for a copper matrix in the composite. Therefore, the hardness of graphite did not directly influence the measured hardness. An indenter was pushed into a material in the indentation hardness test like a Vickers hardness test, Brinell hardness test and etc. The indenter deformed a material plastically. This led to the work hardening. In this study, because graphite particles were pushed into a copper plate, copper in the vicinity of the graphite particle was deformed and work hardened. Because the hardness of the deformed copper was considered to be influenced by the preparation conditions, the hardness of graphite, $H_{\mathrm{g}}$, could be changed by the conditions. As a practical matter, the hardness of graphite, $H_{\mathrm{g}}$, in 


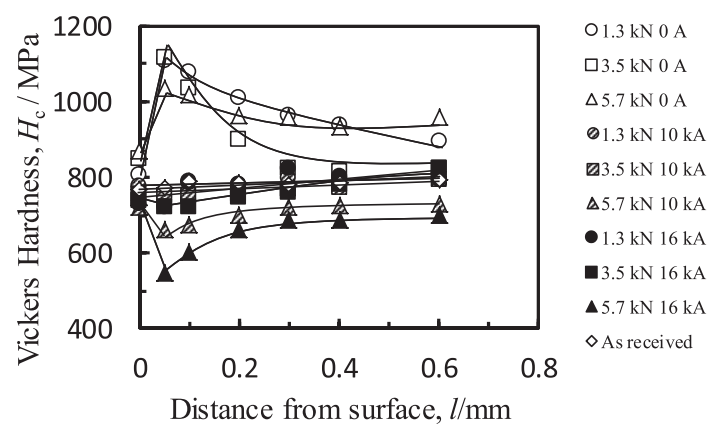

Fig. 14 Relation between Vickers hardness and depth from surface.

the expressions was due to the hardness of copper around the particle. Here, a spot welding was composed of compression, energization under compression and removal of compression. Even if the copper in the vicinity of the graphite particle was fused, the copper near the graphite particle could deform. It could not be determined using eq. (3) and eq. (4) to express the experimental data. Because the rule of mixture given by eq. (3) and eq. (4) are applicable for the properties of bulk composite, the further study was needed to understand the mechanism of the reinforcement of the composite prepared in this study.

Figure 14 showed the relation between the Vickers hardness and the depth of the surface of the plate. For the composite prepared without an electrical current flow, the Vickers hardness at the depth of $0.05 \mathrm{~mm}$ became larger than that at the surface. Subsequently, the hardness decreased with an increase in the depth. The graphite particles which were pushed into the surface transformed the copper plate. The transformation on the surface was easily relaxed by the change in volume of the copper plate surface, but the volume could not change freely inside of the copper plate. Therefore, the hardness at the depth of $0.05 \mathrm{~mm}$ became larger than that at the surface due to the work hardening. In addition, the hardness gradually decreased because the work hardening did not influence deeper.

In the case of the composite prepared with an electrical current flow, generally, the Vickers hardness at the depth of $0.05 \mathrm{~mm}$ became smaller than the surface. Subsequently, the hardness increased with an increase in the depth. The decrement of the hardness tended to become large with increases in the compressive load and electrical current. The graphite particles were scarcely observed at the depth of $0.05 \mathrm{~mm}$. The copper plate was softened by the annealing. In addition, the hardness gradually increased, because the annealing did not influence deeply. From the view point of heat conduction, the temperature at the copper surface which contacted with the graphite particles was the highest, the temperature in a cooper plate decreased with an increase in the depth. Therefore, it was anticipated that the hardness decreased with an increase in the depth. As described earlier, during spot welding, the compression process occurred. This compression caused the deformation of the surface, and made the surface hardened.

\section{Conclusion}

The copper plates which contained graphite particles between them were spot-welded to prepare the graphite dispersed copper composite on a copper plate. The results obtained were summarized as follows:

(1) The composite which was prepared only by the compression of graphite particles without an electrical current flow was produced by plunging the relatively small graphite particles. The carbon content in the composite increased with the repetition number of the compression and the compressive load.

(2) When an electrical current was energized through the sample at the compression, the copper around the graphite particle melted locally. The graphite particles partially or wholly dissolved into copper melt. Undissolved graphite particles adhered to the copper by the melting. The graphite particles were precipitated from the molten copper under cooling. The carbon content in the composite became higher than that prepared without an electrical current flow.

(3) The Vickers hardness of the copper matrix in the composite and the volume fraction of graphite was expressed by the rule of mixtures given by eq. (3) and eq. (4).

\section{REFERENCES}

1) R.J. Hamilton: IEEE Trans. Ind. Appl. 36 (2000) 1682-1687.

2) P. Jenei, J. Gubicza, E.Y. Yoon, H.S. Kim and J.L. Lábár: Compos. Pt. A-Appl. Sci. Manuf. 51 (2013) 71-79.

3) Y. Feng and S.L. Burkett: Comput. Mater. Sci. 97 (2015) 1-5.

4) P. R. Subramanian, D. E. Laughlin: Phase diagrams of binary alloys. Monograph series on alloy phase diagrams, Materials Park, OH: ASM International 10 (1994) 109.

5) M.M.N. Abdul and S. Yokoyama: Mater. Trans. 58 (2017) 11-15.

6) S. Yokoyama, Y. Takashima, M. Nor, Y. Murata, H. Kanematsu, J. Sasano, M. Izaki: AMPT Sept (2012) 1-8.

7) The Chemical Society of Japan: Kagaku Binran Kiso Hem. Edit. 3, (Maruzen, Tokyo, 1984) II-494.

8) The Chemical Society of Japan: Kagaku Binran Kiso Hem. Edit. 3, (Maruzen, Tokyo, 1984) II-239.

9) W.D. Callister, Jr. and D.G. Rethwisch: Materials Science and Engineering 9th edit., (John Wiley and Sons, Asia, 2011) 276.

10) H.S. Kim: Mater. Sci. Eng. A 289 (2000) 30-33.

11) David R. Lide, CRC Handbook of Chemistry and Physics, 88th Edition, (Taylor \& Francis, 2007) 4-56.

12) David R. Lide, CRC Handbook of Chemistry and Physics, 88th Edition, (Taylor \& Francis, 2007) 4-61. 